\title{
HIGH VOLTAGE / HIGH RESOLUTION STUDIES OF METAL AND SEMICONDUCTOR INTERFACES
}

\author{
K.H. Westmacoll, U. Dahmen \\ National Center for Electron Microscopy, Materials and Chemical Sciences Division, \\ Lawrence Berkeley Laboratory, Berkeley, Ca 94720, USA
}

\section{ABSTRACT}

The application of high resolution transmission electron microscopy to the study of homo- or hetero-phase interface structures requires specimens that meet stringent criteria. In some systems the necessary geometric imaging conditions are established naturally, thus greatily simplifying the analysis. This is illustrated for a diamond-hexagonal/diamond-cubic interface in deformed silicon, a $\Sigma 99$ tilt toundary in a pure aluminum bicrystal, and a germanium precipitate in an aluminum matrix.

\section{INTRODUCTION}

The strength of materials is strongly influenced by the presence of interfaces such as grain or interphase boundaries. Consequently, fundamental studies of the structure of interfaces will ultimately lead to a better understanding of the mechanical behavior of materials.

In recent years the availability of transmission electron microscopes with sub- $2 \AA$ point resolution has allowed atomic resolution imaging of interfaces to be extended to the close-packed metals. The purpose of this short contribution is 1) to emphasize the importance of optimizing the specimen geometry and quality to ensure attainment of the necessary contrast and resolution of interfacial structure and 2) to present brief summaries of three recent high resolution studies of interfaces in metals and semiconductors. Although not all the examples were specifically designed as an interface study, the work provides a clear illustration of three different types of interface, a heterophase interface in a semiconductor ( $\mathrm{Si}$ ), a homophase interface (grain boundary) in a metal (Al), and a heterophase metal/semiconductor interface (Al-Ge). 


\section{EXPERIMENTAL DETAILS}

An ideal specimen for high resolution imaging is one that is thin $(<100 \AA)$ flat (not bent) and clean (with a minimum covering of contamination). Most unsuccessful attempts to sbtain an interpretable image are attributable to failure to fulfill one or more of these conditions. For the successful imaging of an interface at atomic resolution further stringent geometrical conditions must also be satisfied [1]. Each crystal forming the interface must have a low index zone axis (but not neccssarily the same zone in both crystals) parallel to the beam and parallel to a vector in the interface plane. These conditions are illustrated in Figure 1 . To achicve atomic resolution throughout the specimen and at the interface the sample is oriented using the biaxial tilt-stage so that these directions are accurately aligned with both the optic axis of the microscope and the electron beam.

Suitable specimens were prepared by chemical or electropolishing techniques or by dimpling and ion beam thinning and examined in the NCEM JEOL-1000 Azomic Resolution Microscope at $800 \mathrm{kV}$ and other high resolution microscopes.

\section{RESULIS}

\section{Hexagonal Silicon (Heierophase Inierfaces in a Semiconductor)}

The observation of thin ribbons of a diamond-hexagonal (dh) form of silicon in hot-indented specimens was first reported by Eremenko and Nikitenko [2,3]. The ribbons were observed to emanate from the highly deformed regions near the indent and propagate on (511) planes of the matrix. This interesting phenomenon was subsequently studied in detail using a variety of techniques, including high resolution imaging, by Pirouz et al. $[4,5]$ and a comprehensive analysis wil! shortly appear in print [6]. It is shown that formation of the dh metastable phase can be treated as a martensitic transiormation having its origin at the interfaces of deformation twin interactions. A schematic illustration of the formation of hexagonal phase in an fce lattice in $\langle 110\rangle$ projection is shown in Figure 2 . Figure 2 illustrates the condition when a secondary twin $T_{2}$ nucleates in a primary twin band $T_{1}$ and subsequently propagates into the matrix $M$. This is the mechanism that gives 
rise 10 the long ribbons on $\{511\}$ habit planes. An example of an hexagonal ribbon imaged at high resolution is given in Figure 3.

\section{Grain Boundaries in ICB Aluminum Bicrystals (Homophase Interfaces in a Metal)}

Unique continuous bicrystal films are formed when aluminum is deposited on a [100] silicon substrate by the lonized Cluster Beam technique (see Ref. 7 for details). Tyro different $\{110\}$ orientation variants of the aluminum forti. which are rolaled rclative to each other by $90^{\circ}$. The resulting microstructure consists of islands of one variant in a sea of the other bounded by $90^{\circ}<110>$ tilt boundaries all of which close on themselves (i.e. the film contains no grain boundary triple points) $[8,9]$. If an annealing treatment at $400^{\circ} \mathrm{C}$ is followed by removal of the silicon substrate a specimen ideal for high resolution TEM observation of the boundaries is obtained. This is because during the annealing the grain boundaries in the aluminum minimize their area by rotating normal to the foil surface. The result is a foil containing the ideal structure depicted in Figure 1. An example of an image of a $\Sigma 99$ symmetrical boundary.obtained under these conditions is given in Fig. 4 . In the center of the image an asymmetrical section is seen to connect two symmetrical [557] boundary segments which exhibit clear atomic relaxations into structural units [10].

Needle Precipitates in Al-Ge (Heterophase Metal/Semiconductor Interfaces.

When a dilute Al-Ge alloy is given a suitable quench/age treatment, long needle-shaped $\mathrm{Ge}$ precipitates form lying parallel to $<100>$ directions in the aluminum [11]. Consequently, if thin foils of this alloy are prepared and viewed along a <100> zone axis, observation of the end-on Ge needles allows a detailed examination to be made of the interface between the germanium and aluminum. It is found $[12,13]$ that a $\langle 110\rangle$ direction in the $\mathrm{Ge}$ is accurately parallel to $\langle 100\rangle \mathrm{Al}$, thus again satisfying the conditions in Figure 1. The precise alignment is attributable to the $\sqrt{2}$ relationship between the lattice parameters of $\mathrm{Al}$ and $\mathrm{Ge}$ whereby [100] $\mathrm{Al}$ almost exactly matches [110] Ge. An example illustrating the image detail of the interface structure as well as the internal precipitate structure is given in Figure 5 . 


\section{CONCLUSIONS}

High resolution imaging is a powerful technique for observing the atomic structure of interfaces. The specimen geometry must be optimized to obtain maximum information on the interface structure.

\section{ACKNOWLEDGEMENTS}

This work was supported by supported by the Director, Office of Energy Research, Office of Basic Energy Sciences, Materials Sciences Division of the U.S. Department of Energy under contract No. DE-AC03-76SF00098.

\section{REFERENCES}

1 U. Dahmen, J. Douin, C.J. Hetherington and K.H. Westmacott, MRS Symp. Proc. 139, 87 (1989)

2 V.G. Nikitenko, Sov. Phys. Sol. St.13, 230 (1971)

3 V.G. Eremenko and Nikitenko, Phys. Stat. Sol. (a) 14, 317 (1972)

4 P. Pirouz, R. Chaim, J. Samuels, Proc. 5th Int. Congress. on "The Structure and Properties of Dislocations in Semiconductors", Moscow, March 1986, in press

5 P. Pirouz, R. Chaim and U. Dahmen, MRS Symposium Proc. 104, 133 (1987)

6 P. Pirouz, R. Chaim, U. Dahmen and K.H. Westmacott, Acta Met. in press

7 Proc. ISIAT Conference, Tokyo, Japan (1986-89)

8 U. Dahmen and K.H. Westmacott, Scr. Met. 22,1673 (1988)

9 M.C. Madden, Appl. Phys. Lett. 55, 1077 (1989)

10 A.P. Sutton and V.Vitek, Phil. Trans. Roy. Soc. London A 309, 1 (1983)

11 U. Dahmen, C. Nelson and K.H. Westmacott, 44th EMSA Proc., G.W. Bailey (cd.), p. 538 (1986)

12 U. Dahmen and K.H. Westmacott, Science 233, 875 (1986)

13 J. Douin, U. Dahmen and K.H. Westmacott, to be submitted to Phil. Mag. 


\section{FIGURE CAPTIONS}

Fig. 1 Schematic illustration of the geometric conditions that must be satisfied to image interface structures at high resolution.

Fig. 2 Schematic diagram showing, in a $\langle 110\rangle$ projection, the formation of a hexagonal ribbon $H$ when a secondary twin $T_{2}$ nucleates inside a primary twin $T_{1}$ and propagates into the matrix $M$.

Fig. 3 Ribbon of diamond-hexagonal material with 1511$\}$ habit plane in hot-indented silicon (micrograph courtesy P. Pirouz)

Fig. 4 Faceted segments of a $\Sigma 9989.4^{\circ}<1 \mathrm{i} 0>$ tilt boundary in aluminum

Fig. 5 Interface structure between aluminum matrix and a germanium needle formed by a precipitation reaction. Note the alignment of $\langle 100\rangle$ Al with $\langle 110\rangle$ Ge. (Micrograph by J. Douin) 


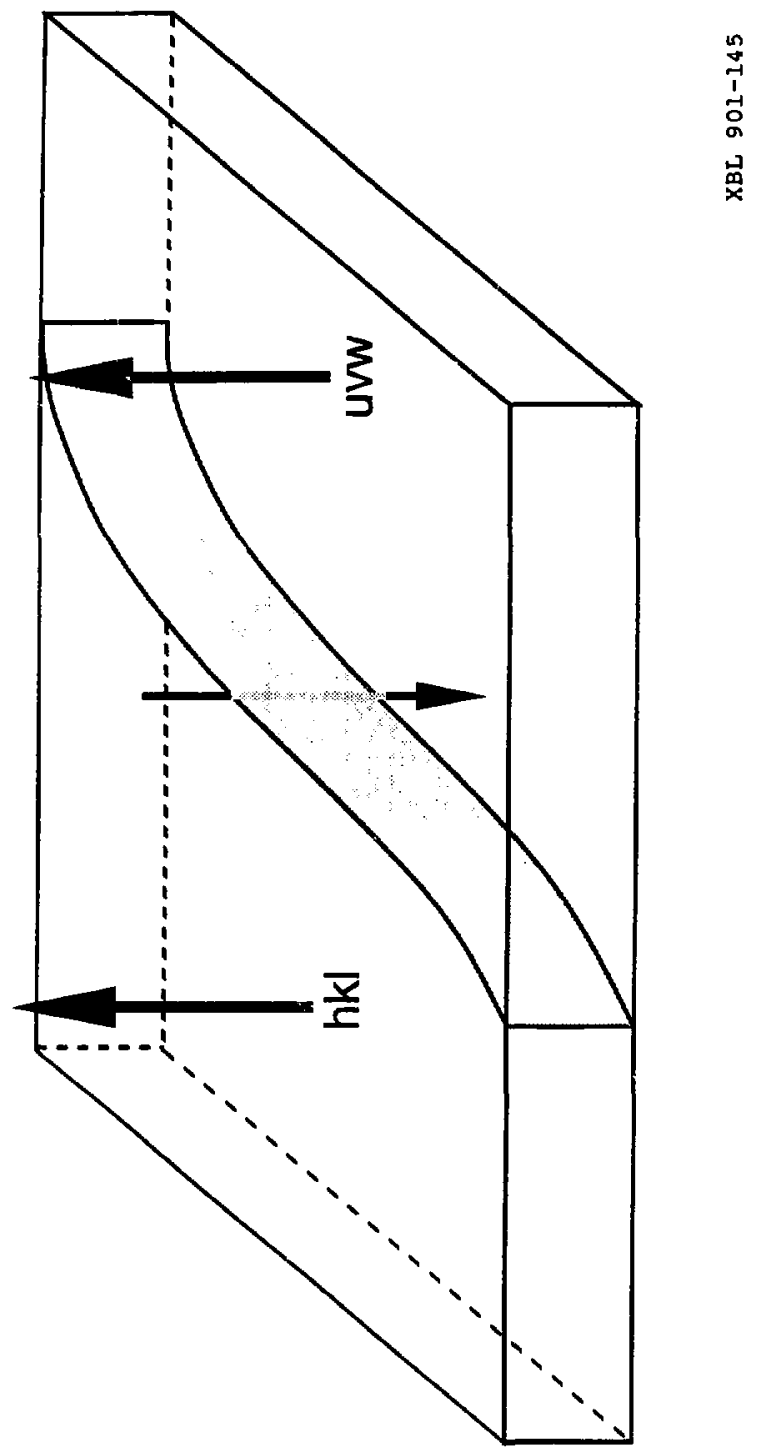

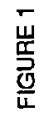




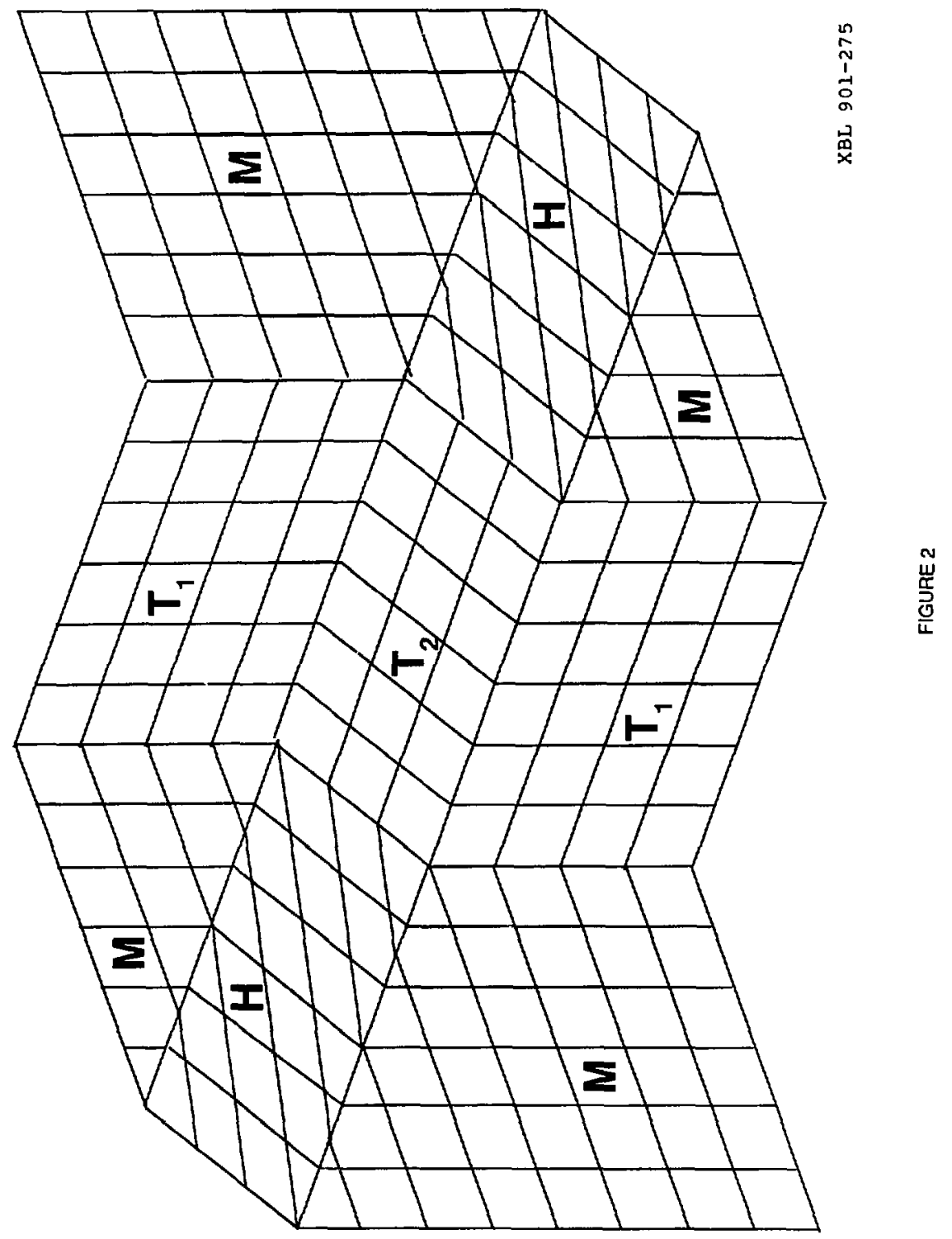




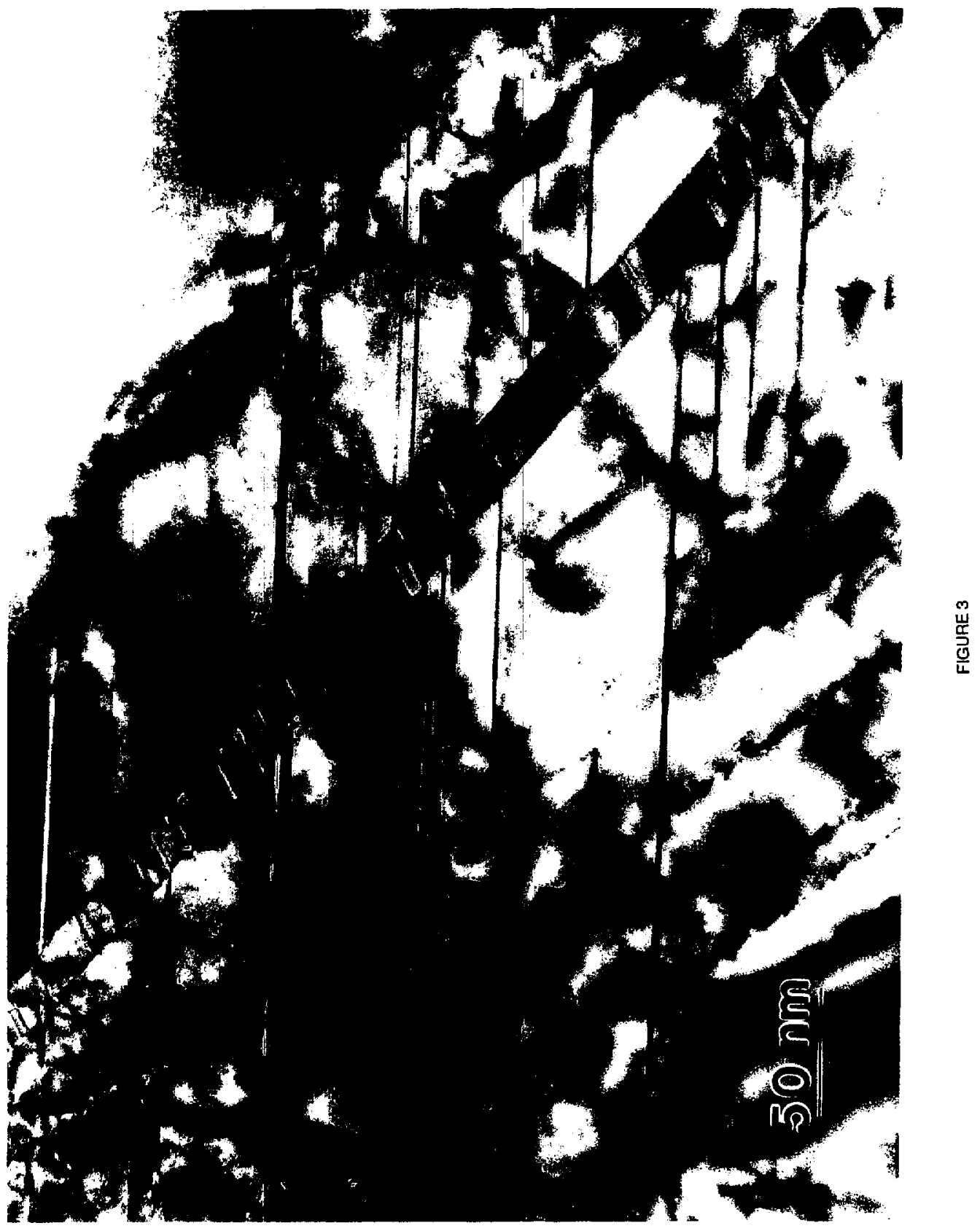




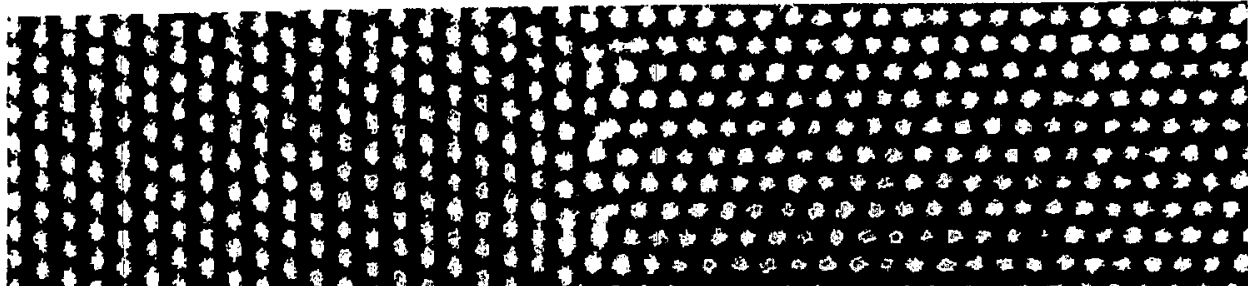

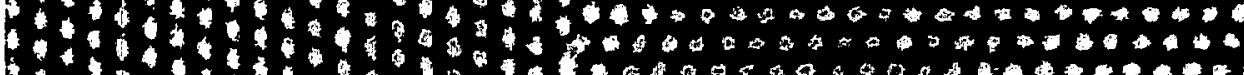

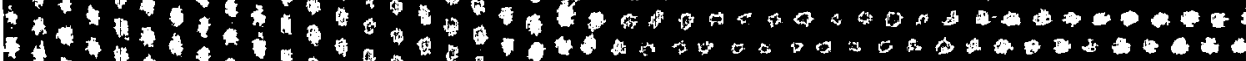

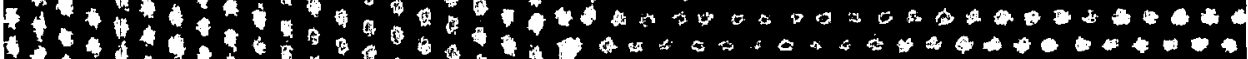

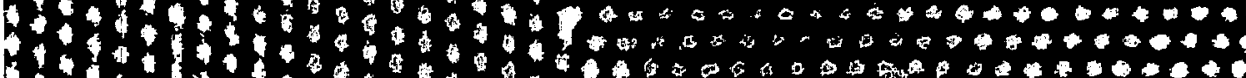

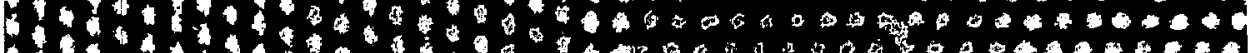

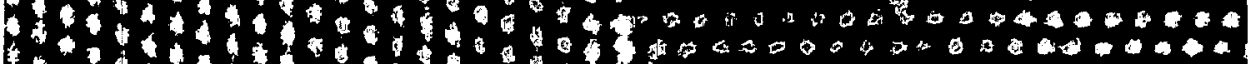

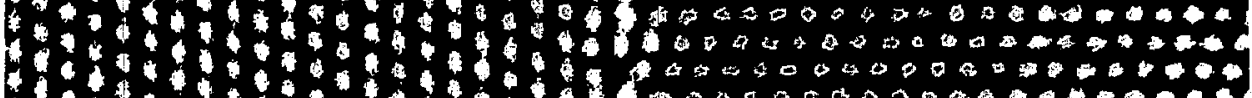
4.

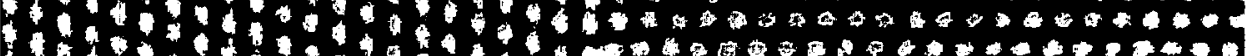

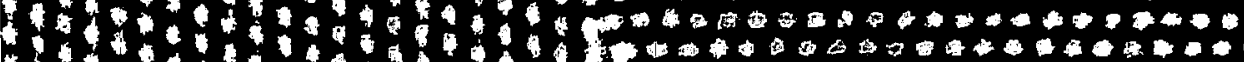

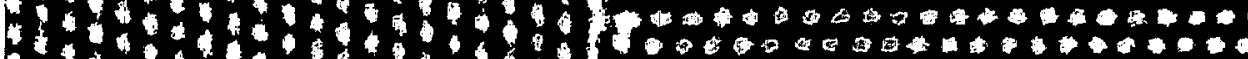

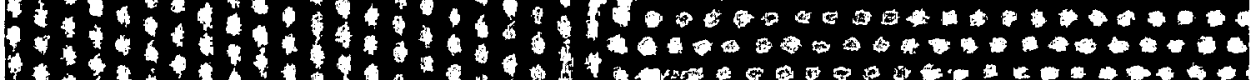

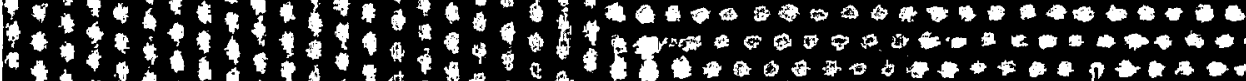

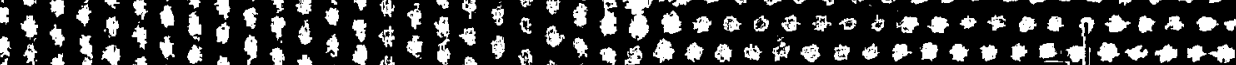

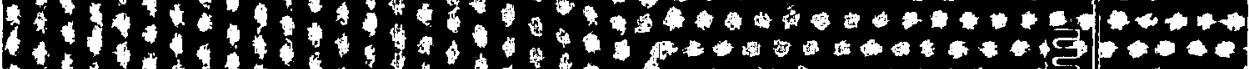

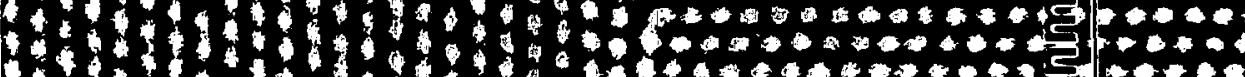

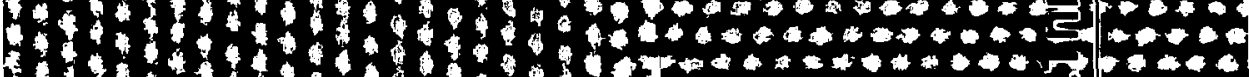

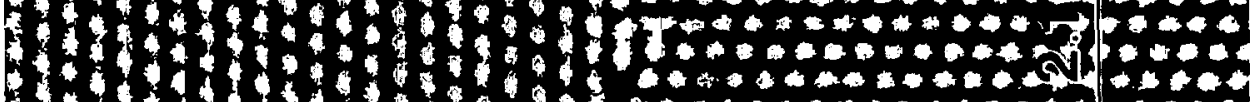

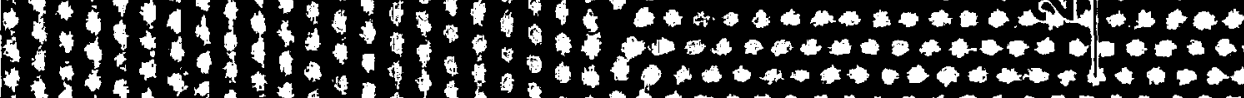

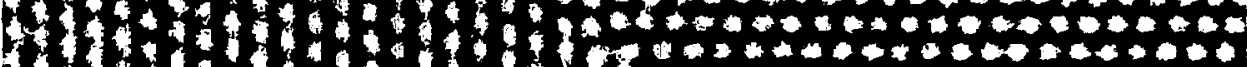

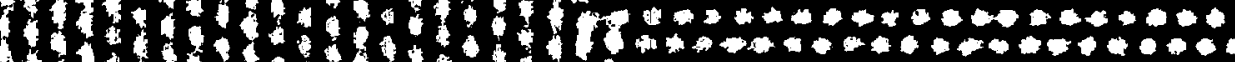

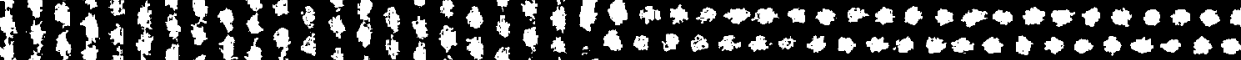

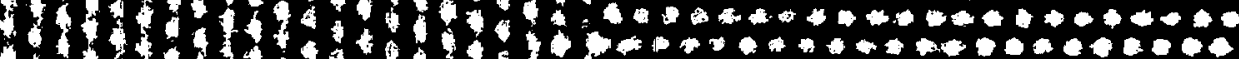

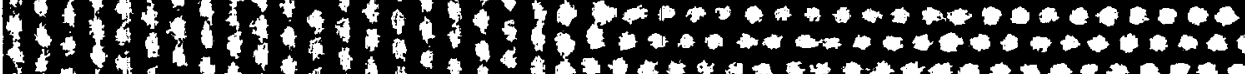

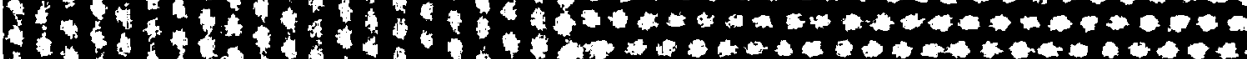

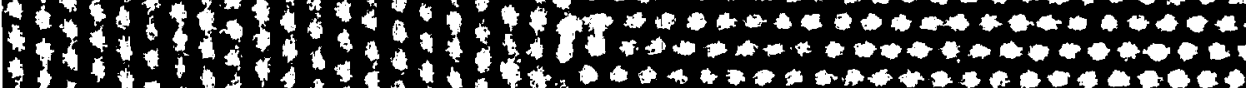

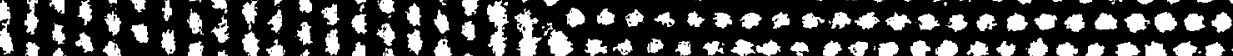

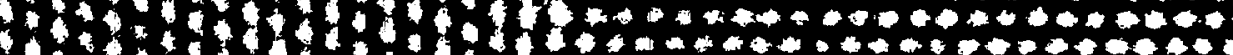

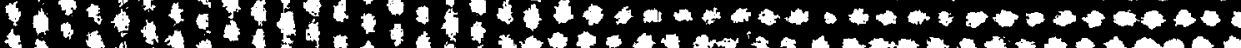

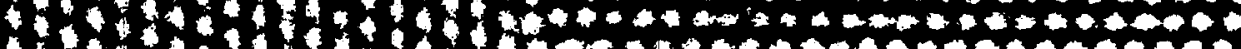

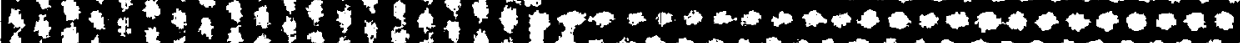

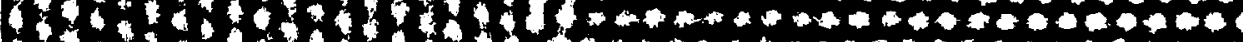

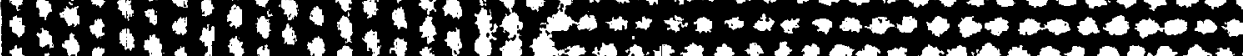

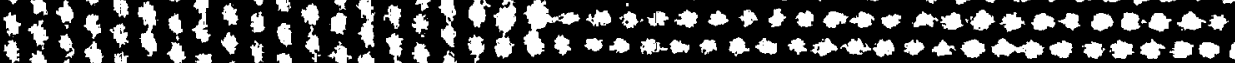

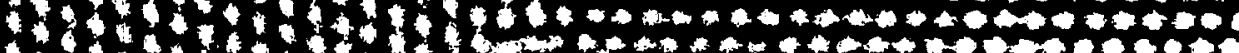

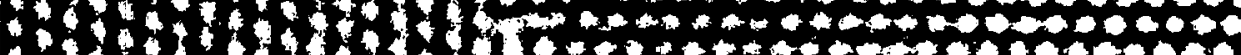

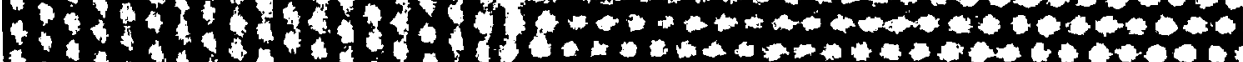

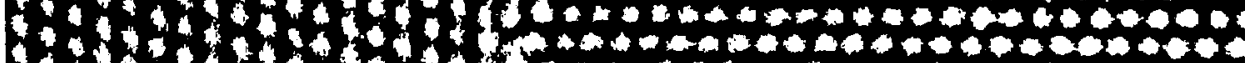

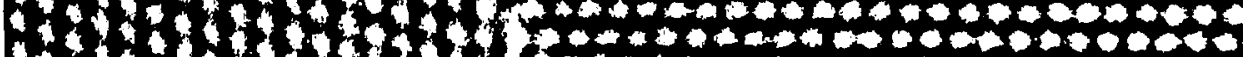

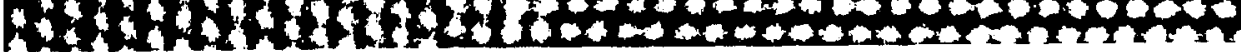




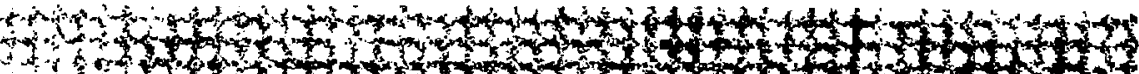

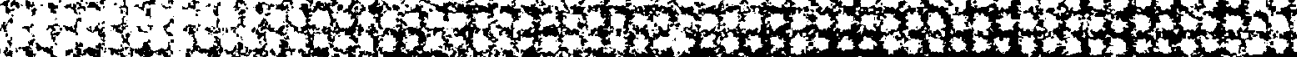

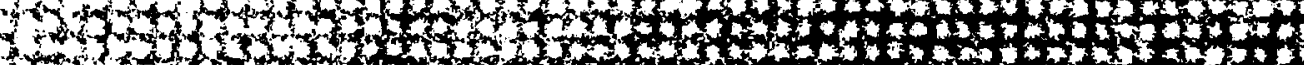

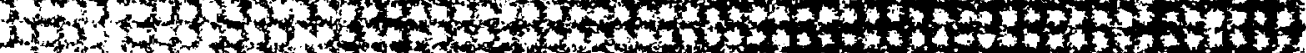

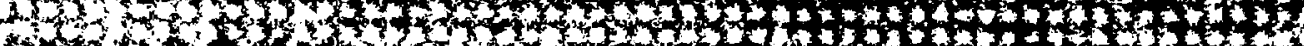

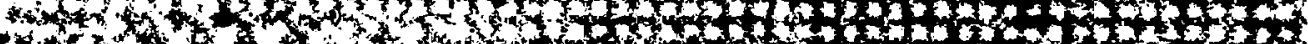

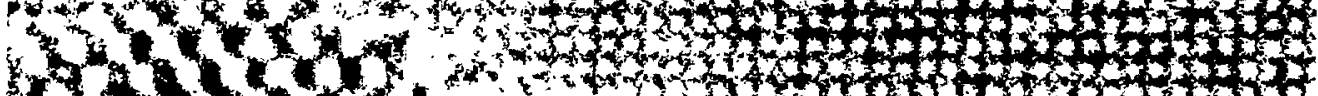

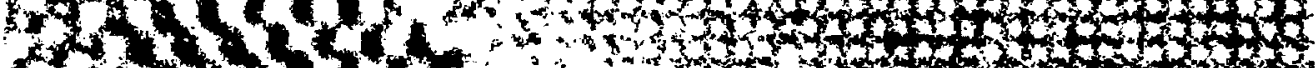

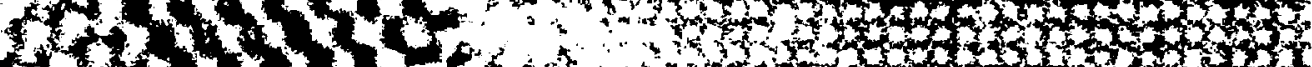

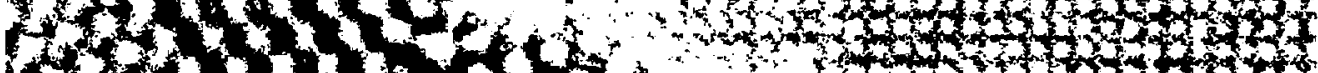

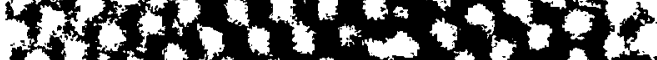

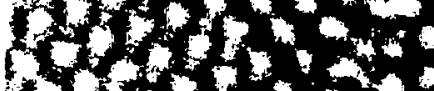

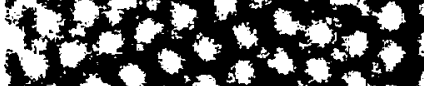

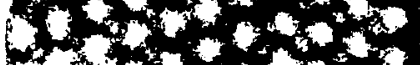

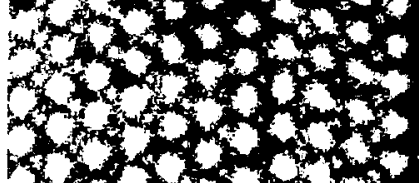

tor.t.
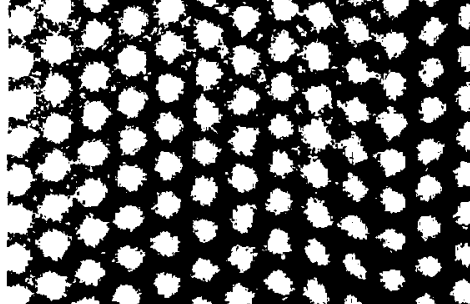

$$
3
$$




\section{DISCLAIMER}

This document was prepared as an account of work sponsored by the United States Government. Neither the United States Government nor any agency thereof, nor The Rezents of the University of California, nor any of their employees, inakes any warranty, express or implied, or assurnes any kepai liability or responsibility for the accuracy, completeness, or usefulness of ; any information, apparatus, product, or process disclosed, or represents that its use would not infriege privately owned righke. Reference herein to any spexific commercial products process, or service by its trade name, trademart, manuficturer, or olher. wise, does not necesserily constituse or imply its endorsenenti. 'recommendation, or fuvosing by the United States Government or any agency thereof, or The Regents of the Unive rsity of ralj- forniz. The views and opiniens of authors exprssedd herein do ' not necessarily state or reflest those of the United Sutes Government or any apency thereof or The Regents of the University of California and shall not be used for advertising or product endorsement purposes.

Lawrence Berkeley Laboratory is an equal opportunity employer. 